\title{
Effect of Microwave Curing on the Tensile Property of Particulate Reinforced Polymer Matrix Composites
}

\author{
Adefemi Adeodu ${ }^{1, *}$, Ilesanmi Daniyan ${ }^{1}$, Temitayo Azeez ${ }^{1}$, Charles Omohimoria ${ }^{2}$ \\ ${ }^{1}$ Department of Mechanical and Mechatronics Engineering, Afe Babalola University, Ado Ekiti, Nigeria \\ ${ }^{2}$ Department of Petroleum and Chemical Engineering, Afe Babalola University, Ado Ekiti, Nigeria
}

Email address:

adeodua@abuad.edu.ng (A. Adeodu), afolabiilesanmi@yahoo.com (I. Daniyan), mrjibs4real@yahoo.com (T. Azeez), Charles_4real@yahoo.com (C. Omohimoria)

\section{To cite this article:}

Adefemi Adeodu, Ilesanmi Daniyan, Temitayo Azeez, Charles Omohimoria. Effect of Microwave Curing on the Tensile Property of Particulate Reinforced Polymer Matrix Composites. Advances in Materials. Vol. 4, No. 3, 2015, pp. 67-74. doi: 10.11648/j.am.20150403.14

\begin{abstract}
Polymer composites by and large found suitable for many specific applications in the field of electrical, electronics, marine, aerospace and microelectronics. Thus a new technique for processing polymer composites has been explored and one such is microwave curing. The roles of microwave in the post curing of polymer matrix composites cannot be under estimated, as it has the capacity to improve the mechanical properties of the composite produced. The aim of the study is to determine the effect of microwave post curing on the tensile property of aluminum reinforced and carbon black reinforced unsaturated polyester composites. This effect was compared with that post cured using conventional oven with the objective of investigating the significance of microwave curing on the tensile strength of the produced composites. A specific study comprising of aluminum filled polyester based composite and carbon black filled polyester based composite were investigated using two different composite curing methods (microwave and conventional thermal heating). The investigation, through experimentation was based on mechanical property (tensile strength) of the produced composites. Comparing the results of the post-curing of the composites using microwave and conventional methods, there is direct relationship between the tensile strength and the percentage weight fraction of the fillers with respect to the post curing methods. 30\% aluminum filled, post cured in microwave has $0.01 \mathrm{MPa}$ tensile strength, 20\% aluminum filled (microwave) has $0.0076 \mathrm{MPa}$ while $30 \%$ aluminum filled (conventional oven curing) has $0.0092 \mathrm{MPa}$ and $20 \%$ aluminum filled (conventional oven curing) has $0.0068 \mathrm{MPa}$.It was concluded that post-curing of the particulate composites through microwave is able to improve the tensile strength better as compared to thermal conventional method.
\end{abstract}

Keywords: Autoclave, Curing, Microwave, Polymer- Matrix Composites, Tensile Strength

\section{Introduction}

Electromagnetic energy has been employed for many years for industrial applications, including wood drying and bread processing [1]. There are several ways in which electromagnetic energy can be applied, such as induction, radio-frequency (RF) or microwave [1]. The main difference is the frequency at which these techniques operate. Depending on the material to be processed, the different frequencies can offer different levels of performance [1]. Although RF and microwave operate in a similar way, microwaves can offer better uniformity. However, both RF and microwave are usually limited to dielectric materials with specific dipolar properties [1].

Particular composites are commonly used today in many aerospace and industrial applications [2]. They offer a wide range of attractive material properties, both mechanical and physical, that cannot be achieved using conventional engineering alloys [2]. These enhanced materials properties are the direct result of the interaction between the matrix and the reinforcement [3].

In a particulate composite materials system, the reinforcement strengthens the matrix both extrinsically, by load transfer to the particle reinforcement, and intrinsically, by increasing dislocation density [3-4]. The interaction between the particulate reinforcement and the matrix is the basis for the enhanced physical and materials properties associated with particulate composite materials systems. Composite materials properties can be tailored to meet specific engineering requirements by selecting a particular reinforcement and varying the amount added to the matrix. 
In this fashion, the physical and mechanical properties of the composite materials system can be controlled with some independence [5].

Increasing the reinforcement volume in a composite system increases mechanical properties, such as elastic modulus, ultimate strength, and yield strength, while reducing the thermal expansion and, in some cases, the density of the composite system. Unfortunately materials properties such as ductility and fracture toughness typically decrease with increasing reinforcement volume [2].

The increase in both the elastic modulus and strength (ultimate and yield) is believed to be due to the difference in thermal expansion between the reinforcement particles and the matrix during solidification and curing. During the production of these composites, both the reinforcement and matrix are heated to processing temperature, brought to curing condition of matrix, and then allowed to cool. The thermal contraction of the matrix during cooling is typically much greater than that of the reinforcement, which leads to a geometric mismatch [2]. At the particle-matrix interface, this geometrical disparity creates mismatch strains that are relieved by the generation of dislocations in the matrix originating from sharp features on the ceramic reinforcement. Discontinuously reinforced matrix composite materials systems are commonly used in applications that require high specific materials properties, enhanced fatigue resistance, improved wear resistance, controlled expansion. Additionally, composite may be designed to yield a materials system that offers multiple roles [6]. Some examples of multiple roles that particulate composite materials systems offer include high strength and fatigue resistance for aerospace and mechanical applications, moderate strength and neutron absorption capabilities for nuclear applications, high strength and wear resistance for heavy equipment applications, and impact/energy dissipation for armor applications [6]. The correct selection of reinforcement is very important in yielding desired resultant materials properties. An improper reinforcement selection may lead to less-than-desirable composite materials properties, difficulty in fabrication of end product, and high cost [7]. The aim of the study is to determine the effect of microwave post curing on the tensile property of aluminum reinforced and carbon black reinforced unsaturated polyester composites. This effect was compared with that post cured using conventional oven with the objective of investigating the effectiveness of microwave curing on the tensile strength of the produced composites.

\section{Literature Review}

Much work has been carried out in processing of both thermoset and thermoplastic composites. Attention will be paid predominantly to thermoset composites due to their relevance to the current study. In terms of mechanical performance, significantly varying levels of success have been reported.
Nightingale [8] compared autoclave cured composites to microwave post-cured, autoclaved composites and full microwave cured composites. The flexure test results showed that microwave post-cured composites produced the lowest mechanical performance, with the conventional autoclave cured composites producing the highest. Lee and Springer [9] even reported microwave curing of multidirectional composites as unsuccessful where no cure was achieved. Other studies have shown that microwave heating produced an improvement in the mechanical and interfacial properties. This is believed to be due to better adhesion between the fibre-matrix interface (in the case of carbon-epoxy composites) as carbon fibres absorb most of the microwaves and therefore 'locally' heat the interface first, as opposed to relying on conduction/convection as reported by Wei et al. [10] and also possibly due to a reduction in thermal residual stress as microwaves heat through the material. Certain studies, such as those carried out by Boey and Yue [11-12], reported an increase in elastic modulus but a decrease in tensile strength for microwave cured composites compared with thermally cured ones. The inconsistency in the results obtained by past research makes it difficult to draw a clear conclusion. It is believed that this can be attributed to three reasons. First is due to the different equipment employed by the researchers. This is critical as in many cases, microwave field homogeneity is not achieved and therefore the measured performance will depend on the location of the sample within the chamber. Secondly by the different experimental techniques employed, e.g. some used time and power as reference, whereas others used temperature; some employed pressure, others did not, etc. And finally, due to the different materials used. The curing mechanism and its interaction with microwaves differ between materials of different chemical structures.

In term of compressive strength, M. Akay et al [13] investigated the moisture absorption behaviour of kevlar49/epoxy-resin laminates when the samples were cured using autoclave and microwave oven. They concluded that moisture absorption of the specimens deteriorates approximately $5 \%$ per $1 \%$ absorbed moisture. Jian Zhou et al [14], through research proved that curing of epoxy resins with maleic anhydride as the curing agent using microwave curing technique increased the compressive strength when compared with the thermal curing technique. They also proved that the amount of maleic anhydride used as curing agent was reduced by about $5 \%$. Thus, concluding that microwave processing of polymer is an efficient and energy-saving technology.

Bambang Soesatyo et al [15], investigated polycarbonate sandwich joined with a fast cured epoxy adhesive and found that microwave cured adhesives had higher tensile bond strength when processed with addition of Sterling carbon black dopant polycarbonate butt joint specimens. They also concluded that high bond strength in microwave cured resulted in a uniform stress level across the joint surface. S. L. Bai et al [16], compared the mechanical behavior of 
epoxy resin cured by microwaves and one cured thermally and concluded that, microwave cured resin have a little higher tensile strength and young's modulus than thermally cured resins because of greater homogeneity. Further, the tensile strength and young's modulus of microwave cured resins increased with the strain rate. S. L. Bai et al [17], investigated unidirectional continuous E-glass fibre/epoxy composites cured using both thermal and microwave. Mechanical behaviour of the composites was studied by in situ transverse tensile tests and they concluded that fibermatrix interface of microwave cured is stronger than that of thermally cured composites also more voids exist in microwave cured composites then thermal cured composites when rupture mechanism was analyzed. This difference was noted due to the shorter time and lower applied pressure of microwave curing composites. T. Chaowasakoo et al [18], studied fly ash/epoxy composites cured by both thermal and microwave curing methods and results were investigated using differential scanning calorimeter. They concluded that the tensile strength of the microwave cured composites increased with increasing fly ash content in microwave cured composites, where as tensile strength decreased in thermally cured composites. T. Chaowasakoo et al [18], studied fly ash/epoxy composites cured by conventional thermal and microwave curing methods and concluded that when results were investigated and determined using differential scanning calorimeter that the composites cured by microwave consumed shorter cure time and had higher ultimate strengths especially impact strength, and strain at break than those by the conventional thermal cure.

\section{Methodology}

\subsection{Material and Equipment Selection}

\subsubsection{Aluminum Powder Overview}

For the purpose of this research, the flake type, known as pyro powder was used. It composed of very small particles with less than $1 \mu \mathrm{m}$. Pyro powder is better selected for composite manufacturing due to the particle sizes, which eventually contributed to the weight of the composites. Other exceptional properties in a composite manufacturing include low density, corrosion resistance, high thermal and electrical conductivity, excellent machinability, good response to variety of finishing process and ability to avoid porosity.

Table 3.1. Summary of properties and composition of Aluminum powder.

\begin{tabular}{ll}
\hline Shape & Flaky \\
\hline Composition & $\mathrm{Al}_{2} \mathrm{O}_{3}$ due to strong affinity for oxygen, Polystyrene, Stearin. \\
Appearance & Silvery white and odourless powder \\
Particle Size $(\mu \mathrm{m})$ & $<1 \mu \mathrm{m}$ \\
True Density $\left(\mathrm{g} / \mathrm{cm}^{3}\right)$ & 2.70 \\
Boiling Point $\left({ }^{\circ} \mathrm{C}\right)$ & 2467 \\
Melting Point $\left({ }^{\circ} \mathrm{C}\right)$ & 660.1 \\
Molecular Weight $(\mathrm{g} / \mathrm{mol})$ & 29.92 \\
Specific Heat $@ 25^{\circ} \mathrm{C}\left(\mathrm{Cal} / \mathrm{g}^{0} \mathrm{C}\right)$ & 0.215 \\
Thermal Conductivity $@ 20^{\circ} \mathrm{C}\left(\mathrm{Cal} / \mathrm{s} . \mathrm{cm} .{ }^{0} \mathrm{C}\right)$ & 0.50 \\
Co-efficient of Expansion@ $20-100 \mathrm{deg} . \mathrm{C}$ & 24.0 \\
Modulus of Elasticity & 69 \\
Specific gravity & 2.6989 \\
Crystallography & Cubic structure, face centred \\
\hline
\end{tabular}

\subsubsection{Polyester Resin Overview}

There are two principal types of polyester resin used as standard laminating systems in the composite industry. Orthophthalic polyester resin is the standard economic resin used by many people. Isophthalic polyester resin is now becoming the preferred material in industries such as marine where its superior water resistance is desirable. Most polyester resins are viscous, pale coloured liquids consisting of a solution of polyester in monomer which is usually styrene. The addition of styrene in amount of up to $50 \%$ helps to make the resin easier to handle by reducing its viscosity [19]. The styrene also performs the vital function of enabling the resin to cure from a liquid to solid by cross linking the molecular chains of the polyester, without the evolution of any by products. For the purpose of the research work, the Orthophthalic type of polyester is used (M3903 unsaturated polyester resin). 
Table 3.2. Summary of properties and Composition of M3903 Polyester resin.

\begin{tabular}{|c|c|}
\hline \multirow{6}{*}{ Physical Properties } & Viscous Pale colour liquid with pungent styrene smell. \\
\hline & $1.54^{\circ} \mathrm{C}$ Boiling point (for styrene). \\
\hline & $1.194 \mathrm{Kg} / \mathrm{m}^{3}$ Density (base polymer) \\
\hline & $1.080 \mathrm{Kg} / \mathrm{m}^{3}$ (polymer solution) \\
\hline & 4.5mmHg Vapour pressure \\
\hline & 90\% Purity \\
\hline Chemical Name & $\begin{array}{l}\text { 1, 3-Benzene dicarboxylic acid, Polymer with 1, } 4 \text { Cyclohexane dimethy ethanol, 2, } 2 \text { dimethy } 1,3 \text {, Propane diol and } 2 \text {, } \\
\text { 5- furandione. }\end{array}$ \\
\hline Composition & $\begin{array}{l}25 \% \text { Propylene Glycol, } 21 \% \text { Phthalic anhydride, } 16 \% \text { Malic anhydride, } 38 \% \text { Styrene Monomer and } 2 \% \text { Additive } \\
\text { making } 100 \% \text { unsaturated Polyester resin. }\end{array}$ \\
\hline Molecular Formula & $\left(\mathrm{C}_{8} \mathrm{H}_{6} \mathrm{O}_{2}, \mathrm{C}_{8} \mathrm{H}_{6} \mathrm{O}_{4}, \mathrm{C}_{5} \mathrm{H}_{12} \mathrm{O}_{2}, \mathrm{C}_{4} \mathrm{H}_{2} \mathrm{O}_{3}\right)_{\mathrm{n}}$ \\
\hline Average Molecular Weight & 2200 \\
\hline Method of detection & Infra red Spectroscopy \\
\hline Toxic or Hazardous/ Impurities & None (contain less than $0.1 \%$ monomeric reactants) \\
\hline Additives & $\begin{array}{l}\text { 1, 2, Benzendiol } 2 \text { methyl wt } \% \\
1,4 \text {, Benzendiol } 2 \text { methyl wt } \%\end{array}$ \\
\hline
\end{tabular}

\subsubsection{Carbon Black Overview}

There are two major types of carbon black namely, thermal black and furnace black. For the purpose of this study, furnace black was used. The reaction time for the production of thermal black is long in compares to the furnace black process. Long reaction time combined with the high temperature required for the thermal decomposition of natural gas feed stock $\left(1300^{\circ} \mathrm{C}\right)$ allows the graphite layer planes of the thermal black to become highly ordered so that only layer surfaces are at the surface of the particle. Conversely, the shorter reaction time used in making furnace black produce layer planes at the surface which are less ordered, resulting in numerous sites for chemical bonds with elastromers. Carbon black with a high amount of surface activity often provides high reinforcement [19]. While thermal black does impart some degree of reinforcement to elastromer. It is most often referred to as an inactive or nonreinforcing black. Other materials include cobalt accelerator and organic peroxide catalyst (MEKP) all mixed in the right proportions.

\subsection{Composite Manufacturing Process}

\subsubsection{Mould Description}

The mould used for the production of the composites is 3gang $2 \times 2$ inches $(50 \mathrm{~mm})$ mould, machined out of brass makes 3 compression test cubes at once. This mould cast cubes in a diagonal arrangement with a detachable brass base plate. Wing nut clamps lock the mould to the base while stainless thumb screws secure halves tightly together. Large screened off upper surface area makes this mould a preferred choice. Optional accessories include an all brass fitted top, or cover plate designed to pour molten substance capping compound down through taper hole for testing tensile strength.

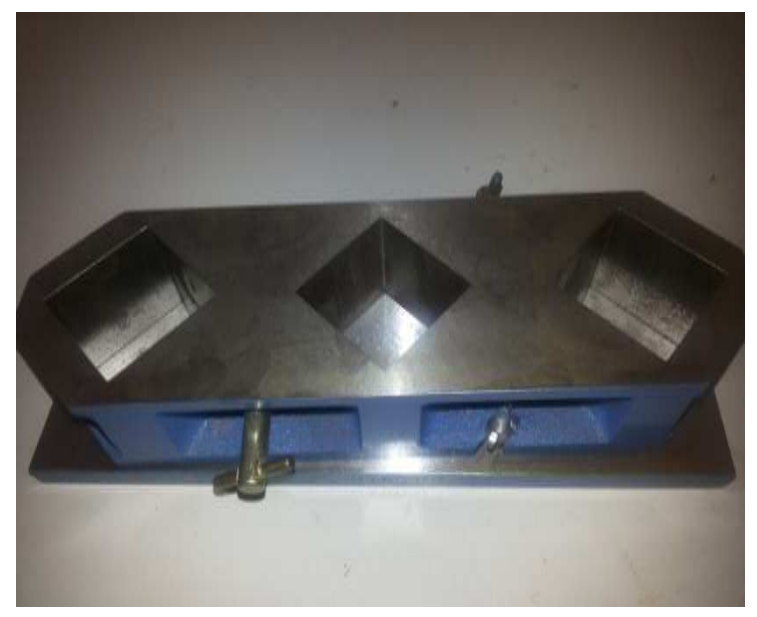

Figure 3.1. 3- gang Mould.

\subsubsection{Specification of Composite Samples}

The next step after the mould design and fabrication was cleaning and preparation of the mould. The preparation was done before pouring the mixture. The plate surface was rubbed with a mould releasing agent (PVC) to facilitate easily removal of composite after solidification.

Functionalization of the aluminum powder and the carbon black was carried out to remove any impurities due to manufacturing process of the conducting fillers. This can be carried out through microwave heating, mainly performed by an electromagnetic cavity where the field homogenization can be efficiently achieved [20].

Mixing of appropriate portions of polyester/aluminum powder and polyester/carbon black with hardener (catalyst and accelerator) to desired weight percentage was done after functionalization of the conducting fillers. Reasonable weight ratios of conducting fillers to polyester resin to hardener to make 500 grams of composites. The weight ratio of polyester resin to hardener used to make composite was $4: 1$. For instant, 500 gram mixture of composite with $30 \%$ conducting fillers requires 262 gram of polyester, 88 grams of hardener 
and 150 grams of the conducting fillers (aluminum powder and carbon black).

Table 3.3 Mixing ratio of Polyester Resin, Hardener and Conducting Fillers.

\begin{tabular}{lllll}
\hline $\begin{array}{l}\text { Percentages of Conducting } \\
\text { Fillers (\%) }\end{array}$ & $\begin{array}{l}\text { Weight fraction of } \\
\text { Polyester Resin } \mathbf{( g )}\end{array}$ & $\begin{array}{l}\text { Weight fraction of } \\
\text { Accelerator/catalyst (g) }\end{array}$ & $\begin{array}{l}\text { Weight fraction of Conducting Fillers } \\
\text { (Aluminum and Carbon Black) (g) }\end{array}$ & $\begin{array}{l}\text { Composites } \\
\text { (glum }\end{array}$ \\
\hline 10 & 394 & 56 & 50 & 500 \\
20 & 320 & 80 & 100 & 500 \\
30 & 263 & 88 & 150 & 500 \\
\hline
\end{tabular}

The following are the set of sequential steps that were used for the specification and lamination of the composites

i. The fabricated moulds are properly prepared and clean

ii. Correct amount of fillers (Aluminum and Carbon black) are weighed into containers

iii.Correct amount of polyester resin, hardener and other additives are weighed and mixed together

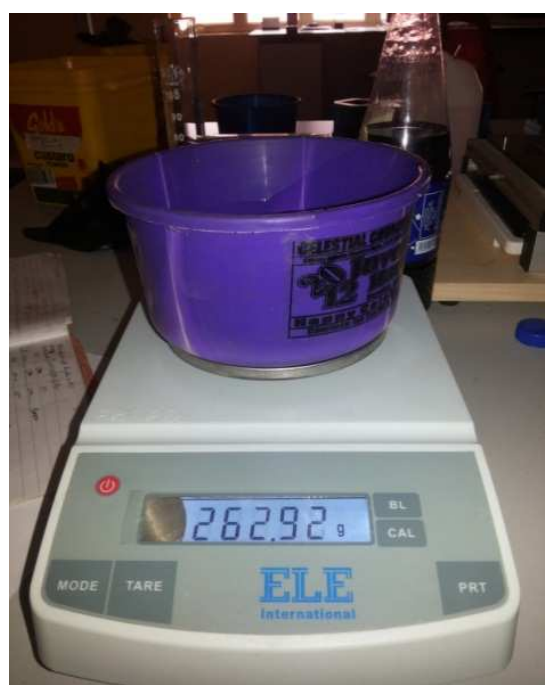

Figure 3.2. Conducting fillers measurement in progress.

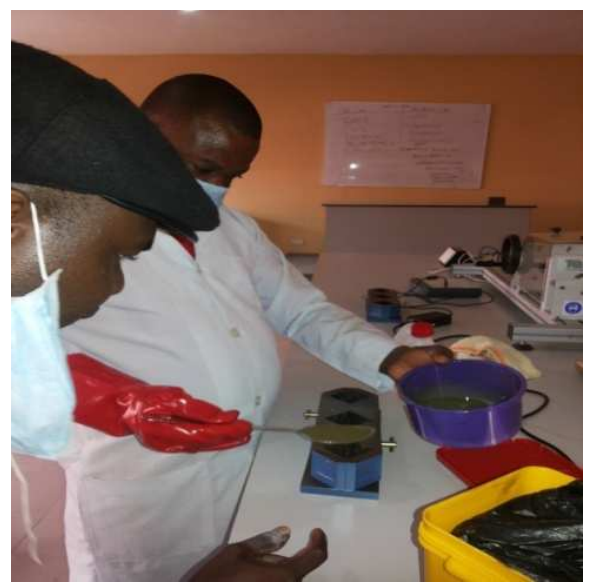

Figure 3.5. Composites Lamination in Progress

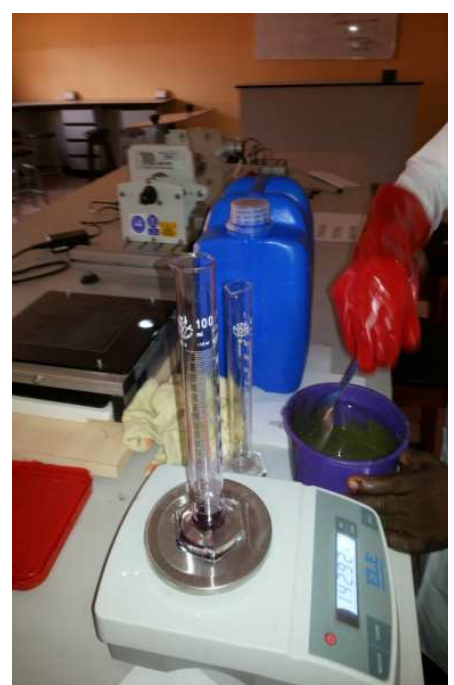

Figure 3.3. Hardeners measurement in progress.

iv. Resin and filler are evenly and slowly mixed with the aid of strong metallic spoon in order to ensure a homogeneous composite mixture

$v$. Each mixture is poured into moulds and allowed to precure under ambient temperature for $24 \mathrm{hrs}$

vi. The pre-cured samples were removed from the moulds and transferred into the ovens for post curing.

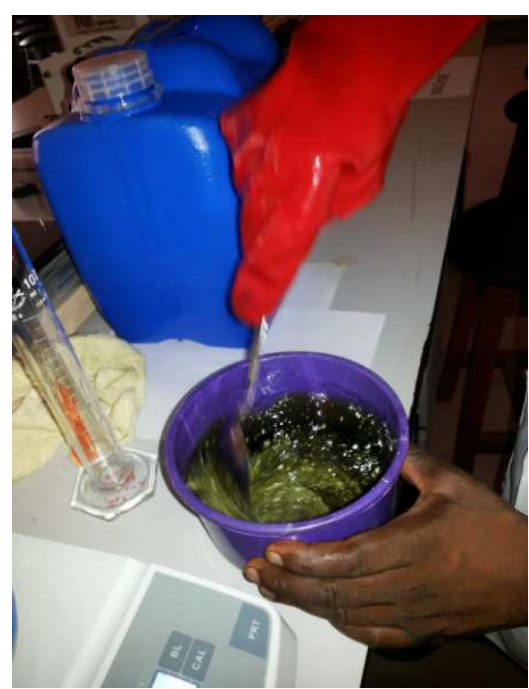

Figure 3.4. Mixing of the Composites in Progress.

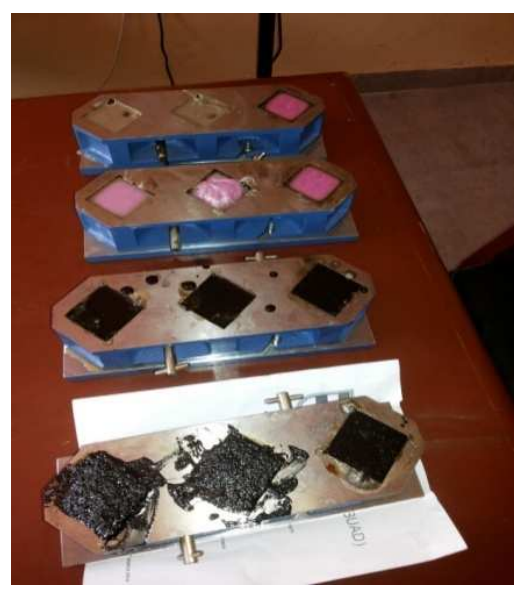

Figure 3.6. Pre-Cured Samples.

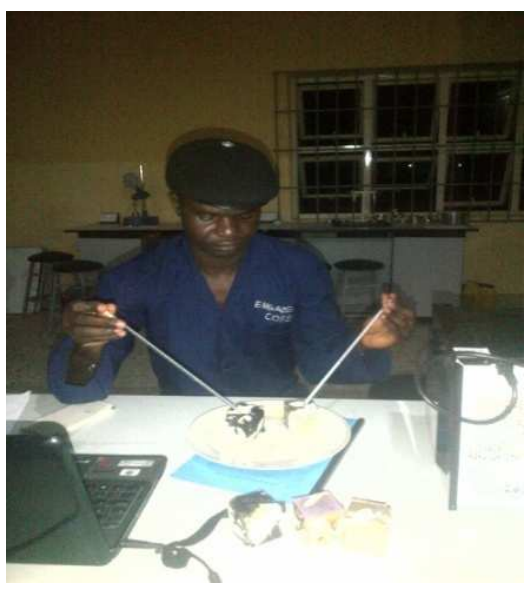

Figure 3.7. Temperature Measurement in Progress.

\subsection{Composite Curing and Monitoring}

The curing of composite involves two different stages. Pre-curing and post-curing, under the influences of electromagnetic and conventional energies. The initial curing of the samples was done under ambient temperature for 24 hours. It is also termed as solidification process, where composite mixtures take on rigid shapes. In this process, 
exothermic reaction takes place, thus leading to materials being cross-linked at room temperature.

At the pre-cure stage, composites have high resistance to forces, but brittle in nature due to random cross linking of molecules of composites. Therefore, to improve the mechanical and other properties of the composites, postcuring of the composites by electromagnetic and conventional heating is required.

Posts curing under the influence of electromagnetic and conventional energies helps resin composites reach their full physical characteristics. For the purpose of this research work, the heating methods were microwave oven and thermal conventional oven. After pre-curing, all the samples (10) were removed from the mould and shared into two equal halves for microwave heating and thermal conventional oven heating respectively. The microwave and the conventional oven are set at constant power level of $800 \mathrm{~W}$. Electromagnetic heating is advisable to be carried out at different stages of lower temperature levels to ensure adequate sample heating and avoid thermal run away problem. In the microwave heating, the samples were first heat up at $20^{\circ} \mathrm{C}$ and power level of $800 \mathrm{~W}$ for $5 \mathrm{~min}$. After wards, the temperature of the oven was increased to $60^{\circ} \mathrm{C}$ at constant power levels of $800 \mathrm{~W}$ till ultimate cure is reached. For the conventional heating, the temperature of the oven was first set at $80^{\circ} \mathrm{C}$ to raise the temperature of the samples for better excitation of the molecules of the composites. After wards, the temperature was increased to $120^{\circ} \mathrm{C}$ to shorten undue lengthen of curing time during which the temperature was taken at every interval of 60 minutes

The temperatures of the samples were taken by laboratory thermometer. The temperature was taken at different spots within the ovens cavity so as to ensure uniformity of temperature within the cavity of the oven and the samples assumed the desired temperature at each stage. In a case where different temperatures were recorded at different spots, the samples which were not at required temperature were reheated until the desired temperature is achieved. After completion of each stage, samples were allowed to cool to room temperature within the cavity of the ovens.

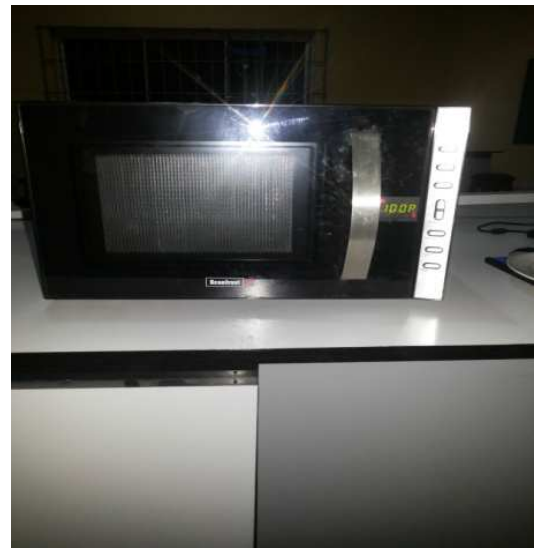

Figure 3.8. Microwave Oven Curing in Progress.

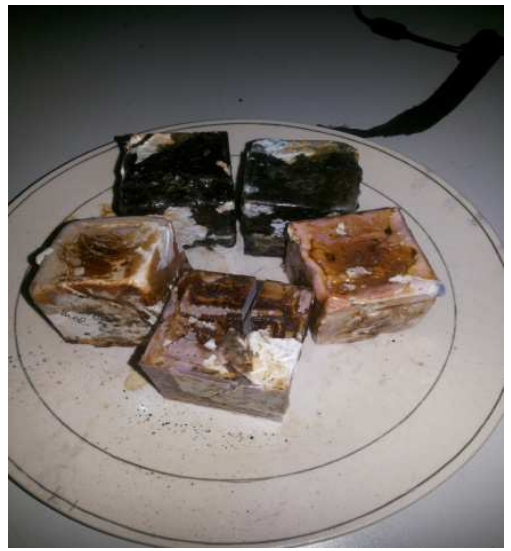

Figure 3.9. Post-Cured Samples.

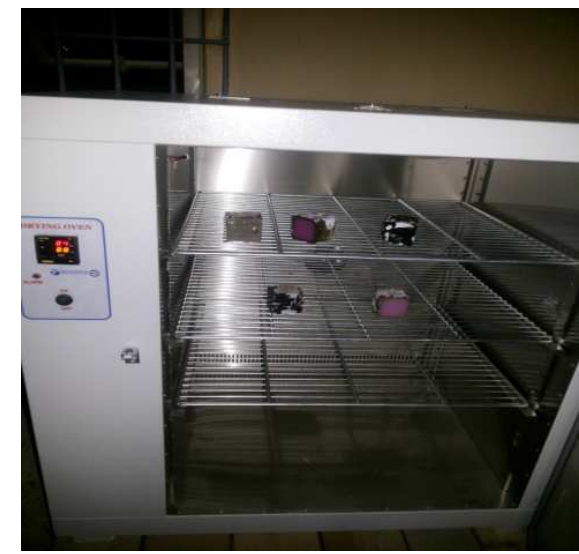

Figure 3.10. Conventional Oven Curing in Progress.

\subsection{Properties Characterization and Testing}

The tensile strength is the maximum strength that material can withstand without breaking. It is the highest point in stress - strain curve. It can be determine by:

Tensile Strength $=$ Maximum Load/ Cross-Sectional Area 3.1

The tensile test was carried out using universal testing machine. The indenters were loaded on the measuring scale. The gauge length of the indenters was set to $3 \mathrm{~cm}$ on the measuring scale which was laid on the compression testing machine diagonally for maximum stability. As shown in figure 3.11, vernier caliper was used to measure the width and thickness of the specimens. The sample loads were placed at a distance between the two indenters on the compression testing machine. Electronic micrometer was connected to the testing machine so that elongation of specimens with increase in the tensile load can be traced. Care must be taken so that samples do not slip from its grip by using the right size of jaw. Select appropriate pressure on the samples that will neither cause breaking of the sample nor slip.

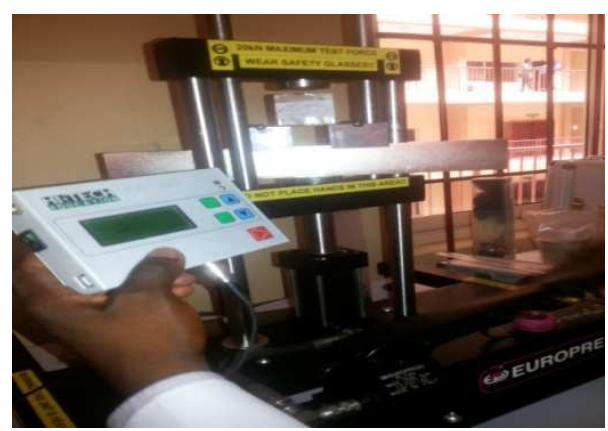

Figure 3.11. Tensile Property measurement in Progress.

\section{Results and Results Discussion}

Comparison of Tensile Strength between the Microwave and Conventional Heating for Polyester-Aluminum Composite and Polyester- Carbon black Composites 
Table 4.1. Maximum Force and Tensile Strength for Microwave Curing.

\begin{tabular}{lllc}
\hline Percentage Weight Fraction of Samples (\%) & Cross - Sectional Area of Samples (mm $\left.{ }^{2}\right)$ & Maximum Force (KN) & Tensile Strength (MPa) \\
\hline $30 \%$ Aluminium filled Polyester Composite & 2500 & 25 & 0.01 \\
$20 \%$ Aluminium filled Polyester Composite & 2500 & 19 & 0.0076 \\
$10 \%$ Aluminium filled Polyester Composite & 2500 & 13 & 0.0052 \\
$20 \%$ Carbon Black filled Polyester Composite & 2500 & 10 & 0.0040 \\
$10 \%$ Carbon Black filled Polyester Composite & 2500 & 8 & 0.0032 \\
\hline
\end{tabular}

Table 4.2. Maximum Force and Tensile Strength for Conventional Oven Curing.

\begin{tabular}{llll}
\hline Percentage Weight Fraction of Samples (\%) & Cross - Sectional Area of Samples $\left(\mathbf{m m}^{2}\right)$ & Maximum Force (KN) & Tensile Strength $(\mathbf{M P a})$ \\
\hline $30 \%$ Aluminium filled Polyester Composite & 2500 & 23 & 0.0092 \\
$20 \%$ Aluminium filled Polyester Composite & 2500 & 17 & 0.0068 \\
$10 \%$ Aluminium filled Polyester Composite & 2500 & 12 & 0.0048 \\
$20 \%$ Carbon Black filled Polyester Composite & 2500 & 7 & 0.0028 \\
$10 \%$ Carbon Black filled Polyester Composite & 2500 & 5 & 0.0020 \\
\hline
\end{tabular}

Figure 4.1a\&b show the relationship between the tensile strength and percentage weight fraction of fillers (aluminium and carbon black) used for both microwave and conventional oven heating respectively. There was a general agreement in the two curves that percentage weight fraction of the particulate reinforcements has high impact on the tensile strength of the two composite systems. There is direct relationship between the tensile strength and the percentage weight fraction of the fillers with respect to the post curing methods. $30 \%$ aluminium filled, post cured in microwave has $0.01 \mathrm{MPa}$ tensile strength, 20\% aluminium filled (microwave)

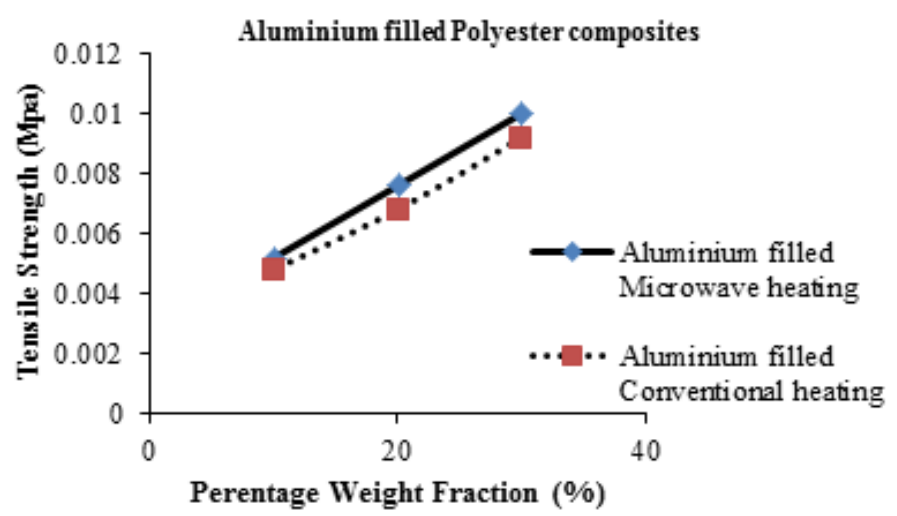

Figure 4.1a. Tensile Strength Curves for varying weight fractions of Aluminium filled Polyester Composite for Microwave and Conventional Oven Curing.

Comparing figures $4.1 \mathrm{a} \& \mathrm{~b}$, it was observed that aluminium filled polyester composite samples have higher tensile strength compared to carbon black filled polyester composite samples both in microwave curing and conventional oven curing. For example, 20\% aluminium filled polyester (microwave curing) has $0.0076 \mathrm{MPa}, 20 \%$ aluminium filled polyester (conventional curing) has $0.0068 \mathrm{MPa}, 20 \%$ carbon black filled polyester has $0.004 \mathrm{MPa}$ has $0.0076 \mathrm{MPa}$ while $30 \%$ aluminium filled (conventional oven curing) has $0.0092 \mathrm{MPa}$ and $20 \%$ aluminium filled (conventional oven curing) has $0.0068 \mathrm{MPa}$. This result can be traced to the statement from the literatures [21-25] that the degree of reinforcement or improved mechanical properties in a composite is dependent on the level of bonding at the matrix - particle interface. Therefore, higher percentage weight fraction of the particulates increase the bonding of the constituent at the interface. Similar impact was experienced for carbon black filled polyester composites.

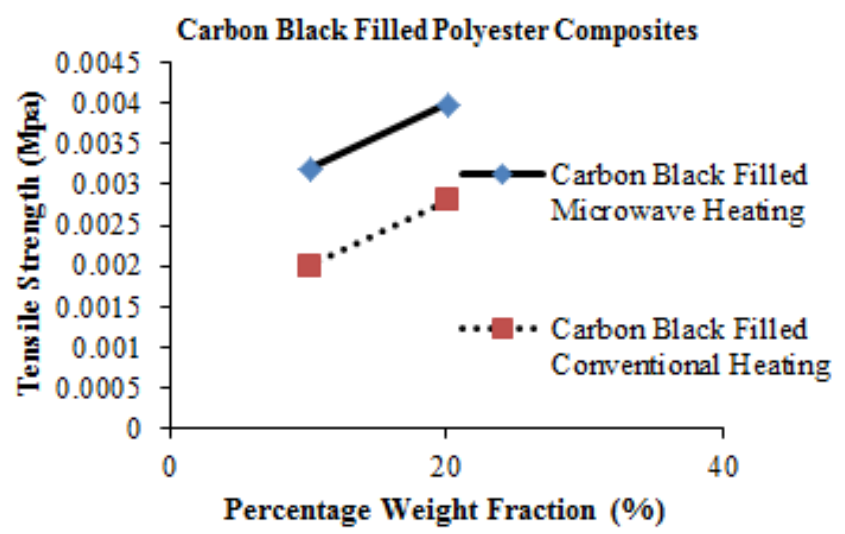

Figure 4.1b. Tensile Strength Curves for varying weight fractions of Carbon Black filled Polyester Composite for Microwave and Conventional Oven Curing.

and $20 \%$ carbon black filled polyester (conventional curing) has $0.0028 \mathrm{MPa}$ respectively. This may be traced to metallic fillers more reactive than non metallic which resulted in higher degree of cross linking in the aluminium filled polyester composite than that of carbon black filled polyester composite.

More observations were made by further comparing the tensile strength of composites curred by microwave oven to 
those curred by conventional oven. It was observed that the two systems of composite have higher tensile strength when curred in microwave oven to those curred using conventional oven. These show the effectiveness of microwave oven curring of composites in improving mechanical properties of composites than conventional oven.

\section{Conclusions}

The use of microwave oven curring of composites improves mechanical properties of composites better than conventional oven.

\section{Recommendations}

The investigation can be further extended to other mechanical properties like impact strength, bending or compression strength.

The microstructural analysis of the produced composites can further investigated to determine the effect of the processing methods on the physical property of the end products in terms of defects like voids

\section{References}

[1] Kwack M., Robinson P., Bismarck A., Wise R., (2011). Curing of composite materials using the recently developed Haphaistos microwave. $18^{\text {th }}$ International Conference on composites materials, Korea, Aug. 21-26.

[2] Hussein Mohammed (2012). The effect of curing time on the mechanical properties of polyester reinforced aluminum particulate composite. Nahrain University college of Engineering Journal. Vol. 15, No 2, pp 197-225.

[3] Hertzberg R.W., (1989). Deformation and fracture mechanics of engineering material, 3rd ed., John Wiley \& Sons.

[4] Sunain Katoch, Vinay Sharma, P. P. Kundu, (2010). Swelling Kinetics of unsaturated polyester layered silicate nanocomposite depending on the fabrication Mmethod, The Open-Access Journal for the Basic Principles of Diffusion Theory, Experiment and Application, 13(1), pp 1-31.

[5] Grayson M. and Eckroth D, Ed., (1982) "Encyclopedia of chemical technology", 3rd ed., Vol. 18, John Wiley \& Sons, p 575 .

[6] Daniel B., Miracle and Steven L. Donaldson (2001). Asm Hand Book, Volume 21, Composite, ASM International Handbook Committee.

[7] Dominick V Rsato and Donal V Rosat., (2003). Plastics Engineering Products Design, Elsevier Ltd, The Boulevard, Langford Lane, Kidlington, Oxford OX5 1GB, UK, p 5.

[8] Nightingale C., (2000).Microwave assisted curing of epoxy resins and composites, $\mathrm{PhD}$ Thesis. University of Manchester, UK.

[9] Lee W., and Springer G., (1984). Microwave curing of composites. Journal of Composite Materials, Vol.18, No.4, pp 387-409.

[10] J. Wei, Y. Chang, B. Thomas and M. Hawley, "Microwave Heating of Thick-Section Graphite Fiber/Epoxy Composites".
Proceedings of ICCM-8, Vol.1, pp10-L-1 to 10-L-10, 1991.

[11] Boey.F., and Lee T., (1991). Electromagnetic Radiation Curing of an Epoxy/Fibre Glass Reinforced Composite. Radiation Physics and Chemistry, Vol.38, No.4, pp 419 - 442.

[12] Yue C., and Boey F., (1993). The Effect of Microwave and Thermal Curing on the Interfacial Properties of an Epoxy/Glass Composite. 2nd International Conference on the Deformation and Fracture of Composites. pp. 12.1-12.8.

[13] M. Akay and S. Kong Ah Mun, (1995). Bearing strength of autoclave and oven cured Kevlar/epoxy laminates under static and dynamic loading. Composites Vol. 26, pp.451-456, (Receive August 1994; revised 7 October 1994).

[14] Jian Zhou, Chun Shi, Bingchu Mei, Runzhang Yuan, Zhengyi $\mathrm{Fu}$, (2003). Research on the technology and the mechanical properties of the microwave processing of polymer, Journal of Materials Processing Technology. Vol.137, pp.156-158.

[15] Bambang Soesatyo, Aaron Blicblau, Elias Siores, (1999). Effect of rapid curing doped epoxy adhesive between two polycarbonate substrates on the bond tensile strength. Journal of Materials Processing Technology. Vol. 89-90, pp.451-456.

[16] Bai S. L., Djafari V., Andreani M. and Francois D. (1995). A comparative study of the mechanical behaviour of an epoxy resin cured by Microwaves with one cured thermally", European Polymer Journal. Vol. 31(9), pp.875-884. (Received 17 January 1994; accepted in final form 27 June 1994).

[17] Bai S. L. and Djafar V. (1995). Interfacial properties of microwave cured Composites", Composites, 26, pp.645-651.

[18] Chaowasakoo T., Sombatsompop N. (2007). Mechanical and morphological properties of fly ash/epoxy composites using conventional thermal and microwave curing methods. Composites Science and Technology. Vol. 67, pp.2282-2291.

[19] National Research Centre (NRC) (1994), Microwave Processing of Materials, National Materials Advisory Board, Commission on Engineering and Technical Systems, National Academy Press, USA, pp.1-7, 11-2, 100, 105.

[20] Prato (2008). Using the Selective Functionalization of Metallic Single-Walled Carbon Nanotubes to Control Dielectrophoretic Mobility. J. Am. Chem. Soc., 130 (25).

[21] Hossain M. R., Hossain M. F., Islam M. A., (2014). Effect of wood properties on the behaviors of wood particle reinforced polymer matrix composites. J. Sci. Res 6(3) Page 431-443.

[22] Azuke F., Aigbodion V. S., Abdulwahab M., Fayomi O. S.I., Popoola A. P.I., Nwoyi C. I., Garba B, (2012). Effect of bone particle on the properties and microstructure of polypropylene-bone ash particulate composites. Results in Physics 2 Page 135-141

[23] [23] Chawla Nikhilesh and Yu Linshen (2001). Mechanical behavior of particle reinforced metal matrix composites. Advanced Engineering Material Vol. 6, page 1438-1656

[24] [24] Shao-Yunfu, Xi-Qiao Feng, Bernd Lauke, Yiu-wing Mail (2008). Effect of particle size particle-matrix interface adhesion and particle loading on mechanical properties of particulate-polymer composites. Science Direct. Composites: part B, 39 Page 933-961.

[25] Hassan S. B., Oghenevweta E. J., Aigbodion V. S (2012). Potential of maize stalk ash as reinforcement in polyester composites. Journal of Minerals Materials Characterization and Engineering. Vol. 11, No 4, Page 445-459. 